\title{
Urine TERT promoter mutations-based tumor DNA detection in patients with bladder cancer: A pilot study
}

\author{
MARK JAIN $^{1}$, DAVID KAMALOV ${ }^{1}$, ALEXANDER TIVTIKYAN ${ }^{1}$, \\ ALEXANDER BALATSKY $^{1}$, LARISA SAMOKHODSKAYA ${ }^{1}$, DMITRY OKHOBOTOV ${ }^{1}$, \\ POLINA KOZLOVA $^{2}$, EDUARD PISAREV $^{3}$, MARIA ZVEREVA $^{4}$ and ARMAIS KAMALOV ${ }^{1}$ \\ ${ }^{1}$ Medical Research and Educational Center, Lomonosov Moscow State University, 119992 Moscow; \\ Departments of ${ }^{2}$ Fundamental Medicine; ${ }^{3}$ Bioinformatics and Bioengineering and \\ ${ }^{4}$ Chemistry, Lomonosov Moscow State University, 119991 Moscow, Russia
}

Received May 7, 2021; Accepted July 9, 2021

DOI: $10.3892 / \mathrm{mco} .2021 .2415$

\begin{abstract}
Telomerase reverse transcriptase (TERT) promoter mutations are the most frequent genetic events in bladder cancer (BC). The aim of the present pilot study was to evaluate the diagnostic potential of urine TERT promoter mutations-based liquid biopsy in patients with an ongoing oncological process, as well as in post-resection patients at risk of $\mathrm{BC}$ recurrence. A total of 60 patients were enrolled, of whom 27 patients had histologically proven BC; 23 had no signs of $\mathrm{BC}$ (control group); and 10 patients underwent transurethral malignancy resection 3-6 months prior to urine donation ('second look' group). Urine TERT promoter mutations were detected using Droplet Digital PCR. Receiver operating characteristic curve analysis revealed significant diagnostic power of the present approach (area under the curve: -0.768). At the cut-off value of tumor DNA fraction $0.34 \%$, the sensitivity and specificity were 55.56 and $100 \%$, respectively. In the positive samples, tumor DNA fraction varied significantly from 0.59 to $48.77 \%$. In the 'second look' group, tumor DNA was detected in 4/10 patients, highlighting the possibility of $\mathrm{BC}$ recurrence with its fraction ranging only from 0.90 to $6.61 \%$. Therefore, urine TERT promoter mutations-based liquid biopsy appears to be a promising tool for BC diagnosis and surveillance. The main study will include recruitment of additional patients, extension of the mutation panel, prolonged follow-up of the post-resection patients, as well as screening of industrial workers exposed to specific carcinogens.
\end{abstract}

Correspondence to: Mr. Mark Jain, Medical Research and Educational Center, Lomonosov Moscow State University, Lomonosovsky pr. 27/10, 119992 Moscow, Russia

E-mail: jain-mark@outlook.com

Key words: bladder cancer, urine liquid biopsy, telomerase reverse transcriptase, digital droplet polymerase chain reaction, cancer relapse, cancer biomarkers

\section{Introduction}

Bladder cancer (BC) is the most common urinary tract malignancy, ranking 9th in frequency and 13th in mortality rate amongst other types of cancer (1). The global age-standardized incidence rate and age-standardized mortality rate of this disease per 100,000 population are 5.7 (2.4 in women and 9.6 in men) and 1.9 (0.87 in women and 3.2 in men), respectively (2). BC tends to occur more frequently in regions with high Human Development Index, and its mortality rate is higher in those regions as well (3). The main risk factors contributing to $\mathrm{BC}$ development are tobacco smoking and occupational exposure to carcinogens (such as various aromatic amines, which are used in dye and rubber industry), and the incidence rate of $\mathrm{BC}$ appears to be declining in regions with an overall decrease in the smoking population (4).

$\mathrm{BC}$ is known to have high recurrence rate. In a population-based analysis Chamie et al (5) demonstrated that $39.1 \%$ of patients experienced recurrence without progression, while $33.0 \%$ had recurrence with progression. Therefore, patients require continuous follow-up over the course of the first 5 years following cancer resection (every 3-6 months), making $\mathrm{BC}$ one of the most costly human cancers in terms of patient management $(6,7)$.

Cystoscopy and urine cytology are widely accepted as routine techniques for the detection, diagnosis and surveillance of BC. Cystoscopy is an effective diagnostic tool, with a sensitivity of $62-84 \%$ and a specificity of $43-98 \%$, depending on the tumor stage and type (8). However, its invasive nature, high cost and high intra- and interobserver variability limit the diagnostic potential of this technique $(9,10)$. In addition, following cystoscopy, patients may suffer from various adverse effects, such as pain during urination (50\%), frequent urination (37\%), hematuria (17\%) and urinary tract infection $(3 \%)(11,12)$. Urine cytology, on the other hand, is a non-invasive approach with a high sensitivity (up to $100 \%)$ for high-grade tumors and a low sensitivity (4-31\%) for low-grade tumors (13). However, interpretation of urine cytology results may be impeded in the presence of urolithiasis, infections and low cellular yield (14). 
Therefore, there is an urgent need to improve the methods for BC diagnosis and follow-up. Due to both recent advances in genomic, epigenomic and proteomic studies of tumor tissue, and the development of sensitive analytical molecular techniques, a new approach to cancer detection has emerged, namely liquid biopsy (15). This technique is based on the analysis of various tumor-related targets circulating in biological fluids, such as blood, urine, saliva and cerebrospinal fluid (16-19). The aforementioned targets include cell-free tumor DNA (tDNA), different types of tumor RNAs, peptides, metabolites, exosomes, endosomes, and even circulating tumor cells $(20,21)$. Direct liquid biopsy and its modifications have been proven to be useful in almost every type of cancer, and currently represent an exponentially growing field of precision medicine $(22,23)$.

As regards BC, urine is the bodily fluid most suitable for examination, as it bathes the surface of urothelial cells for an extended period of time, collecting cell-free tDNA and containing cells exfoliated from the tumor surface. Although the same, at least to some extent, may be said about blood, it was proven that the accuracy of BC diagnosis by means of cell-free tDNA detection is markedly lower in blood compared with urine $(24,25)$. Despite the fact that the usefulness of urine tDNA-based liquid biopsy was successfully demonstrated in various regions worldwide, it is important to mention that the genetic features of a given population may have an impact on the diagnostic efficiency of a set biomarker (26-28). To the best of our knowledge, no clinical studies evaluating the advantages of the aforementioned approach have been conducted to date in the Russian Federation, the population of which has been proven to be genetically distinctive $(29,30)$.

Thus, the aim of the present pilot study was to assess the diagnostic potential of urine tDNA-based liquid biopsy in patients with an ongoing oncological process, as well as in post-resection patients at risk of $\mathrm{BC}$ recurrence.

The telomerase reverse transcriptase (TERT) promoter 'hotspot' mutations C228T and C250T were selected as tDNA biomarkers, since they appear to be the most common in BC tumors (40-75\%) and are completely absent in healthy somatic cells (31-33). Droplet Digital PCR (ddPCR) was the analytical method of choice due to its ability to precisely quantify target DNA, even in case of low allelic frequency (34-37). This approach to detecting TERT promoter mutations was previously proven to be comparable to the next-generation sequencing (NGS)-based validated system 'UroMuTERT' in terms of diagnostic accuracy (38).

\section{Materials and methods}

Pilot study design. The study was approved by the Local Ethics Committee of Medical Research and Educational Center of Lomonosov Moscow University (protocol no. 4/20, dated 27.04.2020) and conducted according to the tenets of the Declaration of Helsinki. All involved patients provided signed informed consent forms. The pilot study design is shown in Fig. 1. In total, 60 patients were enrolled between April 2019 and October 2020; among those, 27 patients had histologically proven non-muscle-invasive BC (BC group); 23 had either no urological disease, or cystitis/benign prostatic hyperplasia with no signs of BC during cystoscopy, which was performed in case of hematuria (control group); and 10 patients underwent transurethral malignancy resection 3-6 month prior to study enrollment, with negative cystoscopy results at the time of biomaterial donation ('second look' group). The clinical and demographic characteristics of the study participants are summarized in Table I. Tumor size was evaluated via transabdominal 3D ultrasonography using SonoAce X8 system (Samsung Medison Co., Ltd.).

Sample collection and processing. Urine samples were collected prior to any diagnostic/surgical manipulations. Intact urine was aliquoted into 4-ml tubes and immediately stored at $-20^{\circ} \mathrm{C}$. After defrosting, each urine sample was thoroughly mixed by pulse-vortexing. DNA was isolated from $4 \mathrm{ml}$ of intact urine using QIAamp Circulating Nucleic Acid Kit (Qiagen $\mathrm{GmbH}$ ) according to the manufacturer's instructions. The incubation during the lysis phase was prolonged for an additional $20 \mathrm{~min}$ to ensure that all remaining cell particles had been eliminated, as the standard manufacturer's protocol was designed for urine supernatant and not for intact biomaterial. Such approach allows to enrich the resulting solution with cell-free tDNA, as well as with genomic tDNA, and to ensure high DNA concentration in the sample.

Synthetic DNA constructs. The reference plasmids were created using pUC19 vector (cloning sites KpnI and HindIII). The mutant inserts were obtained with PCR-amplification with the next primers: Forward primer, 5'-ATAGGTACCAGTGGA TTCGCGGGCACAGA-3' and reverse primer, 5'-AGTCAA AAGCTTCAGCGCTGCCTGAAACT-3' (Evrogen RU, AO). Genomic DNA isolated from liver cancer cells (originating from the HepG2 cell line; cat no. 85011430; MilliporeSigma) was used for amplification of the mutant C228T fragment. To amplify the mutant insert, Q $5^{\circledR}$ High-Fidelity DNA Polymerase (New England BioLabs, Inc.) was used. The final stage was blue-white selection of obtained plasmids. In order to create the plasmid, which contains both C228T and C250T mutations, site-directed mutagenesis was applied to the plasmid with the C228T insert, followed by treatment with DpnI and blue-white selection.

tDNA quantification. Quantification of DNA was performed using the QX200 ddPCR System (Bio-Rad Laboratories, Inc.). Droplet generation, amplification and analysis were carried out following the manufacturer's instructions. Detection of TERT promoter C228T and C250T mutations was achieved using TaqMan Liquid Biopsy dPCR Assays (TERT_C228T, Assay ID Hs000000092_rm and TERT_C250T, Assay ID Hs000000093_rm; Thermo Fisher Scientific, Inc.). The thermocycling conditions were set according to the manufacturer's recommendations for the aforementioned assays (holding stage at $95^{\circ} \mathrm{C}$ for $10 \mathrm{~min}, 40$ cycles of denaturation at $94^{\circ} \mathrm{C}$ for $30 \mathrm{sec}$ and annealing at $60^{\circ} \mathrm{C}$ for $1 \mathrm{~min}$, holding stage at $98^{\circ} \mathrm{C}$ for $\left.10 \mathrm{~min}\right)$. Human Genomic DNA Version 09 (Roche Diagnostics) was used to establish the false-positive droplet threshold in a series of ddPCR experiments with gradually increasing control DNA input. This approach is necessary to distinguish positive and negative clinical samples at lower levels of DNA. The linearity of the tDNA quantification was assessed in a series of experiments with gradual dilutions of 
Table I. Clinical and demographic characteristics of study participants.

\begin{tabular}{|c|c|c|c|}
\hline Parameters & $\begin{array}{l}\text { Bladder cancer group } \\
\qquad(\mathrm{n}=27)\end{array}$ & $\begin{array}{l}\text { Control group } \\
\qquad(n=23)\end{array}$ & $\begin{array}{l}\text { 'Second look' group } \\
\qquad(\mathrm{n}=10)\end{array}$ \\
\hline Age, years ${ }^{\mathrm{a}}$ & $66(26-85)$ & $35(22-65)$ & $65(44-83)$ \\
\hline \multicolumn{4}{|l|}{ Sex, $n$} \\
\hline Male & 22 & 16 & 9 \\
\hline Female & 5 & 7 & 1 \\
\hline Smoking, $\mathrm{n}$ & 7 & 1 & 3 \\
\hline \multicolumn{4}{|c|}{ Tumor stage, $\mathrm{n}$} \\
\hline $0 \mathrm{a}$ & 0 & $\mathrm{~N} / \mathrm{A}$ & $1^{\mathrm{b}}$ \\
\hline $\mathrm{I}$ & 25 & $\mathrm{~N} / \mathrm{A}$ & $9^{\mathrm{b}}$ \\
\hline II & 1 & N/A & $0^{\mathrm{b}}$ \\
\hline III & 1 & $\mathrm{~N} / \mathrm{A}$ & $0^{\mathrm{b}}$ \\
\hline \multicolumn{4}{|c|}{ Tumor grade, $\mathrm{n}$} \\
\hline Low & 16 & N/A & N/A \\
\hline High & 6 & $\mathrm{~N} / \mathrm{A}$ & $\mathrm{N} / \mathrm{A}$ \\
\hline Unknown & 5 & N/A & N/A \\
\hline
\end{tabular}

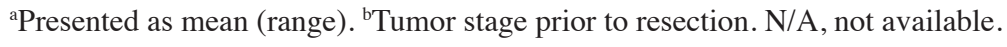

the aforementioned synthetic DNA constructs, carrying TERT promoter C228T and C250T mutations, in the control genomic DNA solution.

Statistical analysis. The results of tDNA quantification are presented as mutated DNA fraction: Mutated DNA/(wild type + mutated DNA), \%. Data were analyzed using IBM SPSS Statistics 22.0 Software (IBM Corp). Receiver operating characteristic (ROC) curve analysis was carried out to establish tDNA fraction cut-off value at optimal sensitivity and specificity. Area under the ROC curve (AUC), overall accuracy, positive and negative predictive values were calculated to evaluate the diagnostic power of TERT promoter mutations-based urine liquid biopsy. Data distribution was assessed using Shapiro-Wilk's test. Due to absence of normal distribution, the correlation between tDNA fraction and tumor size was calculated using Spearman's rank correlation coefficient. The linear association of two variables was expressed with the linear correlation coefficient value $\left(r_{s}\right)$. $\mathrm{P}<0.05$ was considered to indicate a statistically significant difference.

\section{Results}

Preclinical assay validation. In order to combat the issue of false-positive droplets, a series of ddPCR experiments with wild-type control DNA samples were conducted. While still being in a low input range ( $<400$ copies $/ \mu$ l per reaction), the concentration of DNA in each sample was gradually increasing from 50 to 400 copies/ $\mu 1$ per reaction. The maximum number of false-positive droplets per sample using TERT C228T and C250T primers and probes was registered (Fig. S1). According to these results, the false-positive droplet threshold was set to 3 droplets. Thus, all samples with $\leq 3$ positive droplets were considered as mutation-negative by default.
Determination of the quantitative tDNA analysis linearity is a crucial step in the preclinical assay validation. Experimentally calculated tDNA fraction demonstrated a strong linear association with the expected tDNA fraction, achieved through gradual dilution of mutation-positive plasmid in control genomic DNA solution, for both TERT promoter C228T ( $r=0.94)$ and C250T (r=0.99) mutations (Fig. S2).

Evaluation of liquid biopsy analytical parameters. All urine-derived DNA samples of patients from the BC and control groups were successfully analyzed by means of ddPCR. The results of tDNA quantification in each studied sample are summarized in Table SI. ROC curve analysis was implemented to establish the tDNA cut-off value and to determine the analytical parameters of TERT promoter mutations-based urine liquid biopsy (Fig. 2). The AUC appeared to be 0.768 , indicating a significant diagnostic power of the presented model. According to the results of ROC curve analysis, the cut-off value was established at tDNA fraction $0.34 \%$. Samples with $>3$ mutation-positive droplets, but $<0.34 \%$ tDNA fraction, were still considered as mutation-negative.

At the set cut-off value, the sensitivity and specificity were 55.56 and $100 \%$, respectively. tDNA fraction varied significantly from 0.59 to $48.77 \%$ (median, $25.27 \%$; interquartile range, 5.41-31.39\%; Fig. 3). Examples of ddPCR outcomes of TERT promoter mutations detection in representative patients are provided in Fig. S3. Nevertheless, no correlation was observed between tumor size and tDNA fraction $\left(r_{s}=0.174\right.$, $\mathrm{P}=0.535$ ), or tDNA level (expressed in copies/ $\mu 1$ per reaction mixture; $\mathrm{r}_{\mathrm{s}}=0.129, \mathrm{P}=0.646$ ). TERT promoter $\mathrm{C} 228 \mathrm{~T}$ mutation appeared to be the most frequent, as it was detected in 14/27 patients, while C250T mutation alone was detected in $4 / 27$ patients, with both mutations simultaneously observed in 3 cases. 


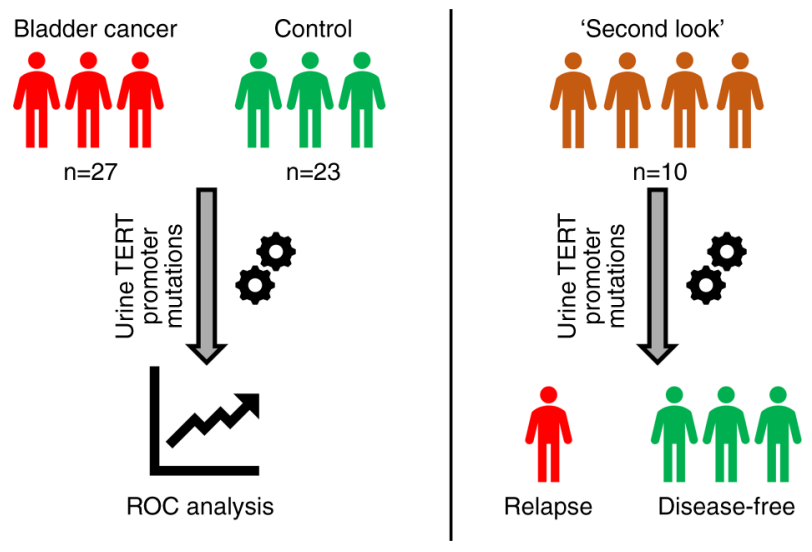

Figure 1. Pilot study design. ROC, receiver operating characteristic; TERT, telomerase reverse transcriptase.

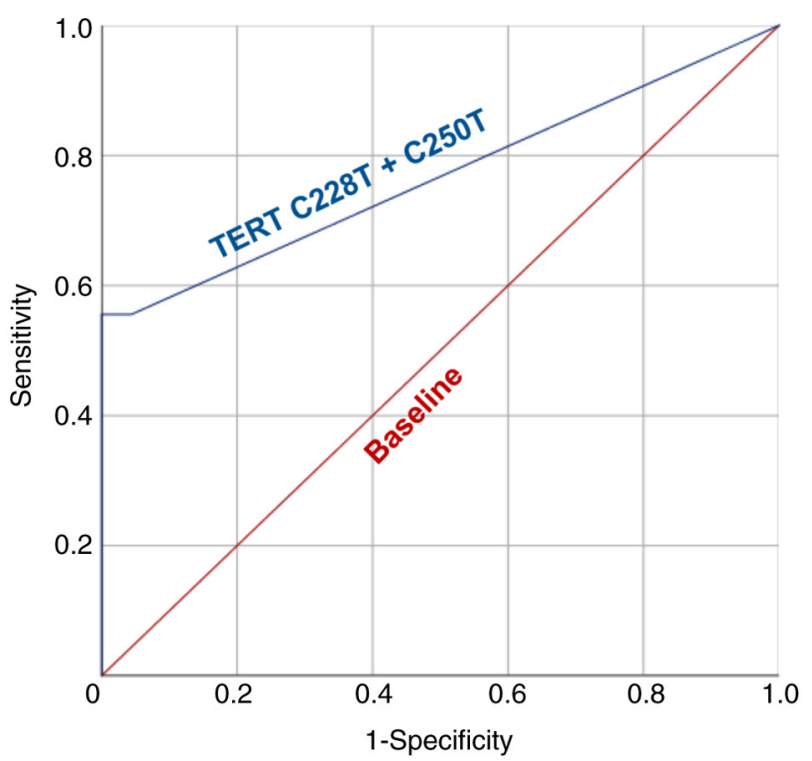

Figure 2. Receiver operating characteristic curve for diagnosis of bladder cancer using urine TERT promoter mutations-based liquid biopsy. TERT, telomerase reverse transcriptase.

Detection of BC recurrence. As previously stated, $\mathrm{BC}$ is characterized by a markedly high recurrence rate; therefore, post-resection patients require regular follow-up diagnostic procedures every 3-6 months (5-7). TERT promoter mutations-based liquid biopsy of the 'second look' group revealed that 3/10 patients had TERT promoter C228T mutated DNA molecules in their urine, and 1/10 had C250T mutated genetic material. The tDNA fraction in mutation-positive patients from the 'second look' group was significantly lower compared with that in the BC group, ranging from 0.90 to $6.61 \%$ (Fig. 4). It is important to mention that cystoscopy was performed immediately after the biomaterial collection was found to be negative, and from the clinical perspective it cannot be stated yet that these patients experience a $\mathrm{BC}$ recurrence. However, the fact that false-positive results were completely absent during the analysis of the control group allows us to hypothesize that BC recurrence has already occurred at the cellular level and its clinical diagnosis is expected in the near future.

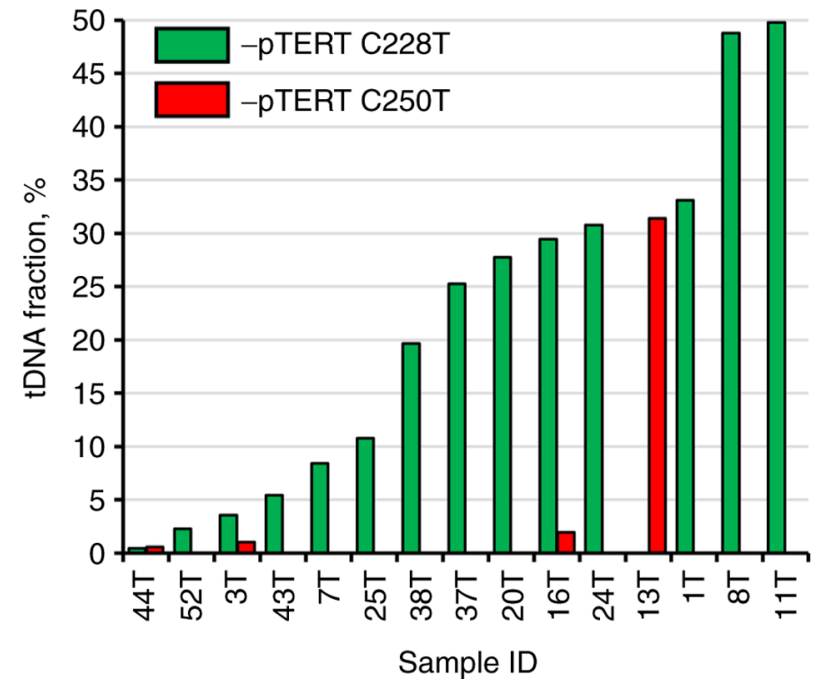

Figure 3. Distribution of tDNA fraction in TERT promoter mutation-positive urine samples from patients in the bladder cancer group. TERT, telomerase reverse transcriptase; pTERT, TERT promoter; tDNA, tumor DNA.

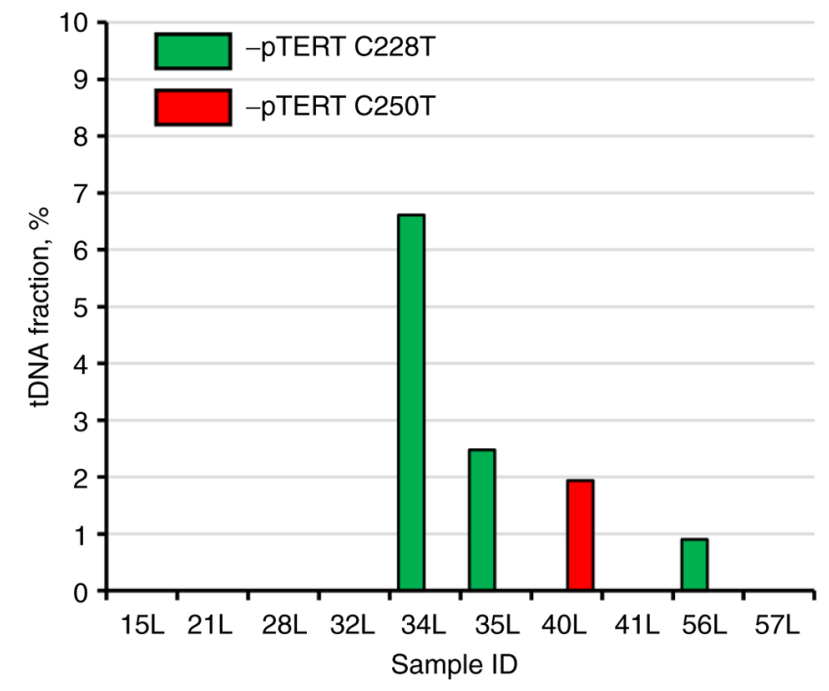

Figure 4. Distribution of tDNA fraction in urine samples from patients in the 'second look' group. TERT, telomerase reverse transcriptase; pTERT, TERT promoter; tDNA, tumor DNA.

\section{Discussion}

ddPCR is a robust and precise analytical tool for absolute quantification of DNA molecules, which is capable of detection of individual tumor-derived copies of genetic material $(39,40)$. Theoretically, a single mutation-positive droplet in a sample indicates the presence of a malignant cell in the organism; however, ddPCR as a method has several limitations, such as non-specific amplification and fluorescent probe degradation, which may cause some droplets to be detected as false-positive (41). Generally, the more amplification events occur (high concentration of DNA in the sample, increased amount of amplification cycles), the more false-positive droplets are detected. If the DNA input is sufficiently large, a few false-positive droplets cannot disrupt the analysis, as the overall tDNA fraction will be 
close to zero and the competently established cut-off value (which may be obtained during comparison of patients with $\mathrm{BC}$ with an adequate group of control patients) will separate false-positive samples from the true-positive ones. However, this is not the case in samples with low DNA input, in which even a single false-positive DNA molecule may easily mislead the operator. In the present study, a simple approach to diminishing the risk of false-positive droplets was demonstrated based on a series of experiments with gradual dilution of wild-type DNA. This approach allows to simplify the ddPCR plate layout during the analysis of clinical samples, eliminating the need to use positive control for mutation calling.

The advent of oncology-related metagenomic projects, such as 'Catalogue Of Somatic Mutations In Cancer' and 'The Cancer Genome Atlas Program', among others, has enabled the development of targeted genetic approaches to the diagnosis of certain types of cancer (42-45). The present pilot study is an example of the implementation of such an approach. TERT promoter mutations have already been proven to be one of the most frequent and reliable detectable genetic alterations in the urine of patients with $\mathrm{BC}$ in various populations $(24,31,38,46,47)$.

The sensitivity of the assay achieved in the pilot study was $55.56 \%$, which is not considerably high, although, as it was previously mentioned, it appears that these mutations are present only in $40-75 \%$ of patients BC $(31,33)$. Furthermore, in other similar urine liquid biopsy studies, TERT promoter mutations were detected in $52-56 \%$ of patients with BC, which was in complete concordance with our results (46-48). Both studied mutations activate TERT gene transcription and are associated with elevated telomerase activity and stable telomere length (49). However, they are subject to different regulatory mechanisms, which may find clinical relevance upon further investigation (50). Thus, it is viable to analyze both mutations, although in the present study the contribution of the C250T mutation to the overall sensitivity was significantly lower compared with that of C228T, as it was detected in only $4 / 27$ vs. $14 / 27$ of the patients, respectively.

TERT promoter mutations, due to their high frequency in $\mathrm{BC}$, may be used in BC diagnosis on their own with an appropriate level of sensitivity, yet it is obvious that a more comprehensive approach (in terms of selected mutations) will have a greater diagnostic power.

Ou et al (24) developed a NGS-based model, which included 5 genes for urine supernatant (TERT, FGFR3, TP53, PIK3CA and KRAS) and 7 genes for urine sediment (TERT, FGFR3, TP53, HRAS, PIK3CA, KRAS and ERBB2), which yielded AUCs of 0.94 and 0.91 , respectively, in the validation cohort. Moreover, the combination of mutations (TERT, FGFR3 and HRAS) and methylation biomarkers (OTX1, ONECUT2 and TWIST1) also led to incredible results, with an AUC of 0.96, as reported by van Kessel et al (51). ddPCR, which was used in the present pilot study, is not suitable for a simultaneous analysis of multiple hotspot mutations in several genes, although extension of the mutations panel up to 8 targets per urine-derived DNA sample is easily achievable without any notable time delay or increase in cost. New perspective genetic $\mathrm{BC}$ biomarkers emerge regularly; for example, Wu et al (52) recently conducted a study dedicated to the sequencing of non-coding elements in $\mathrm{BC}$; it was demonstrated that two neighboring point mutations in the enhancer region of the ADGRG6 gene are quite frequent ( $25 \%$ of patients). Thus, the selection of up to 8 most frequent mutations will not impair the ddPCR-based liquid biopsy and is expected to make it at least on par with the aforementioned NGS-based approaches in terms of diagnostic efficiency, as they are more cost-effective and easier to implement in a common clinical laboratory.

As previously mentioned, no correlation was observed in our pilot study between tumor size and level/fraction of tumor-derived DNA; however, the sample size was not sufficiently large to reach definitive conclusions. Nonetheless, this appears to be counterintuitive and it would be reasonable to hypothesize that, the bigger the tumor, the higher the tDNA fraction, both in the urine and plasma. In fact, this topic is more complex when several other factors are considered.

Recent cancer cell culture studies demonstrated that the cell-free DNA levels did not correlate well with the process of apoptosis and necrosis, thereby providing evidence for the active release of cell-free DNA, the dynamics of which are yet to be uncovered $(53,54)$. Additionally, it is known that tumor growth may be paired with nutrient deprivation of the surrounding tissue and the organism as a whole, which may eventually cause an increase in the overall release of cell-free non-tDNA; thus, theoretically, with the growth of the tumor its DNA fraction value will not grow, as actually both elements of its equation (nominator and denominator) will increase (55). In a large multi-center study it was demonstrated that the tumor-derived cell-free DNA fraction varies significantly in patients with the same type and stage of cancer (56). However, some studies reported a correlation with advanced-stage disease or with a sufficiently large tumor size, starting from $27 \mathrm{~cm}^{3}$ (57,58). Absolute tDNA value (expressed in copies/ $\mu \mathrm{l}$ ) is an alternative to tDNA fraction, although it is highly susceptible to DNA isolation inconsistency and, in our case, to the state of the biomaterial, as intact urine was used, in which the content of exfoliated tumor cells is expected to vary significantly among different patients.

Although TERT promoter mutations are generally considered to be an early event in tumor formation, this does not indicate that all malignant cells carry these genetic alterations (59). Amongst the mutation-positive pilot study participants, 3 patients had TERT promoter C228T and C250T mutations simultaneously, and the tDNA fractions were as follows: In the first patient, 0.45 and $0.59 \%$, respectively; in the second patient, 3.55 and $1.03 \%$, respectively; and in the third patient, 29.46 and $1.93 \%$, respectively. In the third patient, the difference was almost 15 -fold, indicating that the C250T mutation possibly occurred notably later in the course of disease progression. This fact allows us to infer that the same may be applicable in other cases of BC: The tumor may be large, but only a certain proportion of its cells carries the studied mutation. Of note, detection of several hotspot mutations at once and usage in the following calculations of the one with the highest fraction or level can substantially decrease the influence of the discussed phenomenon.

Therefore, a larger sample size, an extended mutation panel and implementation of another tDNA level normalization approach are required to assess the ability of tDNA to reflect the tumor size with more confidence. 
Cell-free tDNA-based liquid biopsy not only carries a great diagnostic potential in patients presenting with at least some clinical BC manifestations, but it is also capable of detecting $\mathrm{BC}$ up to 10 years prior to clinical diagnosis (60). Moreover, it was recently demonstrated that post-radical cystectomy patients with metastatic relapse had significantly higher cell-free plasma tDNA levels compared with disease-free patients during a 3-year follow-up (61). These data, as well as the absence of false-positive results in our pilot study, suggest that mutation-positive patients from the 'second look' group are likely to experience cancer relapse. All patients from this group will be participating in our main study, together with additional recruited participants. We plan to continue their post-malignancy resection follow-up and to monitor the individual tDNA status in the urine.

In conclusion, urine liquid biopsy has promising clinical potential, making it the next possible step in the field of precision medicine. Future incorporation of this non-invasive diagnostic approach into the routine clinical workflow may significantly decrease the number of costly manipulations, such as cystoscopy. Our plans for the main study include recruitment of additional patients, extension of the mutation panel, simultaneous analysis of DNA derived from tumor tissue, plasma and urine, prolonged follow-up of the post-resection patients, as well as screening of industrial workers exposed to specific carcinogens.

There were certain limitations to the present study: The sample size in the present pilot study was not sufficient to reliably reflect the TERT promoter mutation frequency in Russian patients with BC. An increase of the number of study participants in the main study may alter the calculated sensitivity and specificity for this biomarker. Absence of genomic DNA derived directly from the resected tumor limits our knowledge on the actual tumor genotype in the $\mathrm{BC}$ and the 'second look' groups. TERT promoter mutations are also frequently encountered in several other cancer types, such as glioma, melanoma, pancreatic and thyroid cancers (62). Thus, there is a slight possibility that mutation-positive DNA detected in the urine may have originated from another undiagnosed non-BC primary tumor.

\section{Acknowledgements}

Not applicable.

\section{Funding}

The clinical part of the pilot study was carried out within the state assignment of Lomonosov Moscow State University. The preclinical experiments were supported by the Russian Foundation for Basic Research (grant no. 18-29-08040).

\section{Availability of data and materials}

The datasets used and/or analyzed during the current study are available from the corresponding author on reasonable request.

\section{Authors' contributions}

Conceptualization, AK and MZ; methodology, MJ and EP; software, PK and EP; validation, DK, AT, LS and AB; formal analysis, DO; investigation, $\mathrm{MJ}$ and $\mathrm{MZ}$; resources, DK and
AT; raw data generation, MJ and PK; data curation, AT and DK; writing-original draft preparation, MJ; writing-review and editing, $\mathrm{MZ}$ and $\mathrm{AB}$; visualization, DO; supervision, LS; project administration, AK; funding acquisition, AK and MZ. All the authors have read and approved the final manuscript.

\section{Ethics approval and consent to participate}

The study was approved by the Local Ethics Committee of Medical Research and Educational Center of Lomonosov Moscow University (protocol no. 4/20, dated 27.04.2020) and conducted according to the tenets of the Declaration of Helsinki. All involved patients provided signed informed consent forms.

\section{Patient consent for publication}

Not applicable.

\section{Competing interests}

The authors declare that they have no competing interests.

\section{References}

1. Antoni S, Ferlay J, Soerjomataram I, Znaor A, Jemal A and Bray F: Bladder cancer incidence and mortality: A global overview and recent trends. Eur Urol 71: 96-108, 2017.

2. Mohammadian M, Safari A, Bakeshei KA, Asti A, Mohammadian-Hafshejani A, Salehiniya H, Emamiyan M and Khakpour H: Recent patterns of bladder cancer incidence and mortality: A global overview. World Cancer Res J 7: e1464, 2020.

3. Dy GW, Gore JL, Forouzanfar MH, Naghavi $M$ and Fitzmaurice C: Global burden of urologic cancers, 1990-2013. Eur Urol 71: 437-446, 2017.

4. Cumberbatch MGK, Jubber I, Black PC, Esperto F, Figueroa JD, Kamat AM, Kiemeney L, Lotan Y, Pang K, Silverman DT, et al: Epidemiology of bladder cancer: A systematic review and contemporary update of risk factors in 2018. Eur Urol 74: 784-795, 2018.

5. Chamie K, Litwin MS, Bassett JC, Daskivich TJ, Lai J, Hanley JM, Konety BR and Saigal CS; Urologic Diseases in America Project: Recurrence of high-risk bladder cancer: A population-based analysis. Cancer 119: 3219-3227, 2013

6. Picozzi S, Ricci C, Gaeta M, Ratti D, Macchi A, Casellato S, Bozzini $\mathrm{G}$ and Carmignani L: Upper urinary tract recurrence following radical cystectomy for bladder cancer: A meta-analysis on 13,185 patients. J Urol 188: 2046-2054, 2012.

7. Mariotto AB, Robin Yabroff K, Shao Y, Feuer EJ and Brown ML: Projections of the cost of cancer care in the United States: 2010-2020. J Natl Cancer Inst 103: 117-128, 2011.

8. Jocham D, Stepp H and Waidelich R: Photodynamic diagnosis in urology: State-of-the-art. Eur Urol 53: 1138-1150, 2008.

9. Sutton AJ, Lamont JV, Evans R, Williamson K, O'Rourke D, Duggan B, Sagoo GS, Reid CN and Ruddock MW: An early analysis of the cost-effectiveness of a diagnostic classifier for risk stratification of haematuria patients (DCRSHP) compared to flexible cystoscopy in the diagnosis of bladder cancer. PLoS One 13: e0202796, 2018.

10. Glatz K, Willi N, Glatz D, Barascud A, Grilli B, Herzog M, Dalquen P, Feichter G, Gasser TC, Sulser T and Bubendorf L: An international telecytologic quiz on urinary cytology reveals educational deficits and absence of a commonly used classification system. Am J Clin Pathol 126: 294-301, 2006.

11. Biardeau X, Lam O, Ba V, Campeau L and Corcos J: Prospective evaluation of anxiety, pain, and embarrassment associated with cystoscopy and urodynamic testing in clinical practice. J Can Urol Assoc 11: 104-110, 2017.

12. Burke DM, Shackley DC and O'Reilly PH: The community-based morbidity of flexible cystoscopy. BJU Int 89: 347-349, 2002. 
13. Lotan Y and Roehrborn CG: Sensitivity and specificity of commonly available bladder tumor markers versus cytology: Results of a comprehensive literature review and meta-analyses. Urology 61: 109-118, 2003.

14. Raitanen MP, Aine R, Rintala E, Kallio J, Rajala P, Juusela H and Tammela TLJ: Differences between local and review urinary cytology in diagnosis of bladder cancer. An interobserver multicenter analysis. Eur Urol 41: 284-289, 2002.

15. Jung A and Kirchner T: Liquid biopsy in tumor genetic diagnosis. Dtsch Arztebl Int 115: 169-174, 2018.

16. Rothé F, Laes JF, Lambrechts D, Smeets D, Vincent D, Maetens M, Fumagalli D, Michiels S, Drisis S, Moerman C, et al: Plasma circulating tumor DNA as an alternative to metastatic biopsies for mutational analysis in breast cancer. Ann Oncol 25 1959-1965, 2014

17. Millholland JM, Li S, Fernandez CA and Shuber AP: Detection of low frequency FGFR 3 mutations in the urine of bladder cancer patients using next-generation deep sequencing. Res reports Urol 4: 33-40, 2012

18. Pan W, Gu W, Nagpal S, Gephart MH and Quake SR: Brain tumor mutations detected in cerebral spinal fluid. Clin Chem 61: 514-522, 2015.

19. Liang Y, Han J, Jia C, Ma Y, Lan Y, Li Y and Wang S: Effect of endometrial injury on secretion of endometrial cytokines and IVF outcomes in women with unexplained subfertility. Mediators Inflamm 2015: 757184, 2015.

20. Arneth B: Update on the types and usage of liquid biopsies in the clinical setting: A systematic review. BMC Cancer 18: 527, 2018

21. Mathai R, Vidya R, Reddy B, Thomas L, Udupa K, Kolesar J and Rao M: Potential utility of liquid biopsy as a diagnostic and prognostic tool for the assessment of solid tumors: Implications in the precision oncology. J Clin Med 8: 373, 2019.

22. Remon J, García-Campelo R, de Álava E, Vera R, RodríguezPeralto JL, Rodríguez-Lescure Á, Bellosillo B, Garrido P, Rojo F and Álvarez-Alegret R: Liquid biopsy in oncology: A consensus statement of the spanish society of pathology and the spanish society of medical oncology. Clin Transl Oncol 22: 823-834, 2020.

23. Chen $\mathrm{M}$ and Zhao $\mathrm{H}$ : Next-generation sequencing in liquid biopsy: Cancer screening and early detection. Hum Genomics 13: 34, 2019.

24. Ou Z, Li K, Yang T, Dai Y, Chandra M, Ning J, Wang Y, Xu R, Gao T, Xie Y, et al: Detection of bladder cancer using urinary cell-free DNA and cellular DNA. Clin Transl Med 9: 4, 2020.

25. Avogbe PH, Manel A, Vian E, Durand G, Forey N, Voegele C, Zvereva M, Hosen MI, Meziani S, De Tilly B, et al: Urinary TERT promoter mutations as non-invasive biomarkers for the comprehensive detection of urothelial cancer. EBioMedicine 44: 431-438, 2019

26. Lodewijk I, Dueñas M, Rubio C, Munera-Maravilla E, Segovia C, Bernardini A, Teijeira A, Paramio JM and Suárez-Cabrera C: Liquid biopsy biomarkers in bladder cancer: A current need for patient diagnosis and monitoring. Int J Mol Sci 19: 2514, 2018

27. Wang K, Liu T, Liu C, Meng Y, Yuan X, Liu L, Ge N, Liu J Wang $\mathrm{C}$, Ren $\mathrm{H}$, et al: TERT promoter mutations and TERT mRNA but Not FGFR3 mutations are urinary biomarkers in han chinese patients with urothelial bladder cancer. Oncologist 20: 263-269, 2015.

28. Yuan X, Liu C, Wang K, Liu L, Liu T, Ge N, Kong F, Yang L, Björkholm M, Fan Y, et al: The genetic difference between Western and Chinese urothelial cell carcinomas: Infrequent FGFR3 mutation in Han Chinese patients. Oncotarget 7: 25826-25835, 2016.

29. Stepanov VA, Balanovsky OP, Melnikov AV, Lash-Zavada AY, Khar'kov VN, Tyazhelova TV, Akhmetova VL, Zhukova OV, Shneider YV, Shil'nikova IN, et al: Characteristics of populations of the russian federation over the panel of fifteen loci used for DNA identification and in forensic medical examination. Acta Naturae 3: 56-67, 2011.

30. Zhernakova DV, Brukhin V, Malov S, Oleksyk TK, Koepfli KP, Zhuk A, Dobrynin P, Kliver S, Cherkasov N, Tamazian G, et al: Genome-wide sequence analyses of ethnic populations across Russia. Genomics 112: 442-458, 2020

31. Hayashi Y, Fujita K, Matsuzaki K, Matsushita M, Kawamura N, Koh Y, Nakano K, Wang C, Ishizuya Y, Yamamoto Y, et al: Diagnostic potential of TERT promoter and FGFR3 mutations in urinary cell-free DNA in upper tract urothelial carcinoma. Cancer Sci 110: 1771-1779, 2019.
32. Russo IJ, Ju Y, Gordon NS, Zeegers MP, Cheng KK, James ND, Bryan R and Ward DG: Toward personalised liquid biopsies for urothelial carcinoma: Characterisation of ddPCR and urinary cfDNA for the detection of the TERT $228 \mathrm{G}>\mathrm{A} / \mathrm{T}$ mutation. Bladder Cancer 4: 41-48, 2018.

33. Siraj AK, Bu R, Iqbal K, Parvathareddy SK, Siraj N, Siraj S, Diaz MRF, Rala DR, Benito AD, Sabido MA, et al: Telomerase reverse transcriptase promoter mutations in cancers derived from multiple organ sites among middle eastern population. Genomics 112: 1746-1753, 2020.

34. Demaree B, Weisgerber D, Dolatmoradi A, Hatori M and Abate AR: Direct quantification of EGFR variant allele frequency in cell-free DNA using a microfluidic-free digital droplet PCR assay. Methods Cell Biol 148: 119-131, 2018.

35. Crimi S, Falzone L, Gattuso G, Grillo CM, Candido S, Bianchi A and Libra M: Droplet digital PCR analysis of liquid biopsy samples unveils the diagnostic role of hsa-miR-133a-3p and hsa-miR-375-3p in oral cancer. Biology (Basel) 9: 379, 2020.

36. Falzone L, Musso N, Gattuso G, Bongiorno D, Palermo CI, Scalia G, Libra M and Stefani S: Sensitivity assessment of droplet digital PCR for SARS-CoV-2 detection. Int J Mol Med 46: 957-964, 2020

37. La Rocca F, Grieco V, Ruggieri V, Zifarone E, Villani O,Zoppoli P, Russi S, Laurino S, Falco G, Calice G, et al: Superiority of droplet digital PCR over real-time quantitative PCR for JAK2 V617F allele mutational burden assessment in myeloproliferative neoplasms: A retrospective study. Diagnostics (Basel) 10: 143, 2020.

38. Hosen MI, Forey N, Durand G, Voegele C, Bilici S, Avogbe PH, Delhomme TM, Foll M, Manel A, Vian E, et al: Development of sensitive droplet digital PCR assays for detecting urinary TERT promoter mutations as non-invasive biomarkers for detection of urothelial cancer. Cancers (Basel) 12: 3541, 2020.

39. Mao X, Liu C, Tong H, Chen Y and Liu K: Principles of digital PCR and its applications in current obstetrical and gynecological diseases. Am J Transl Res 11: 7209-7222, 2019.

40. Zhang H, Liu R, Yan C, Liu L, Tong Z, Jiang W, Yao M, Fang W and Chen Z: Advantage of next-generation sequencing in dynamic monitoring of circulating tumor DNA over droplet digital PCR in cetuximab treated colorectal cancer patients. Transl Oncol 12: 426-431, 2019.

41. Ruiz-Villalba A, van Pelt-Verkuil E, Gunst QD, Ruijter JM and van den Hoff MJ: Amplification of nonspecific products in quantitative polymerase chain reactions (qPCR). Biomol Detect Quantif 14: 7-18, 2017.

42. Tate JG, Bamford S, Jubb HC, Sondka Z, Beare DM, Bindal N, Boutselakis H, Cole CG, Creatore C, Dawson E, et al: COSMIC: The catalogue of somatic mutations in cancer. Nucleic Acids Res 47: D941-D947, 2019.

43. Tomczak K, Czerwińska P and Wiznerowicz M: The Cancer Genome Atlas (TCGA): An immeasurable source of knowledge. Contemp Oncol (Pozn) 19: A68-A77, 2015.

44. Horn S, Figl A, Rachakonda PS, Fischer C, Sucker A, Gast A, Kadel S, Moll I, Nagore E, Hemminki K, et al: TERT promoter mutations in familial and sporadic melanoma. Science 339: 959-961, 2013

45. Huang FW, Hodis E, Xu MJ, Kryukov GV, Chin L and Garraway LA: Highly recurrent TERT promoter mutations in human melanoma. Science 339: 957-959, 2013

46. Ward DG, Baxter L, Gordon NS, Ott S, Savage RS, Beggs AD, James JD, Lickiss J, Green S, Wallis Y, et al: Multiplex PCR and next generation sequencing for the non-invasive detection of bladder cancer. PLoS One 11: e0149756, 2016.

47. Critelli R, Fasanelli F, Oderda M, Polidoro S, Assumma MB, Viberti C, Preto M, Gontero P, Cucchiarale G, Lurkin I, et al: Detection of multiple mutations in urinary exfoliated cells from male bladder cancer patients at diagnosis and during follow-up. Oncotarget 7: 67435-67448, 2016.

48. Batista R, Lima L, Vinagre J, Pinto V, Lyra J, Máximo V, Santos L and Soares P: TERT promoter mutation as a potential predictive biomarker in BCG-treated bladder cancer patients. Int J Mol Sci 21: 947, 2020

49. Borah S, Xi L, Zaug AJ, Powell NM, Dancik GM, Cohen SB, Costello JC, Theodorescu D and Cech TR: Cancer. TERT promoter mutations and telomerase reactivation in urothelial cancer. Science 347: 1006-1010, 2015.

50. Li Y, Zhou QL, Sun W, Chandrasekharan P, Cheng HS, Ying Z, Lakshmanan M, Raju A, Tenen DG, Cheng SY, et al: Non-canonical NF- $\kappa \mathrm{B}$ signalling and ETS1/2 cooperatively drive C250T mutant TERT promoter activation. Nat Cell Biol 17: $1327-1338,2015$ 
51. van Kessel KEM, Beukers W, Lurkin I, Ziel-van der Made A, van der Keur KA, Boormans JL, Dyrskjøt L, Márquez M, Ørntoft TF, Real FX, et al: Validation of a DNA methylation-mutation urine assay to select patients with hematuria for cystoscopy. J Urol 197: 590-595, 2017.

52. Wu S, Ou T, Xing N, Lu J, Wan S, Wang C, Zhang X, Yang F, Huang Y and Cai Z: Whole-genome sequencing identifies ADGRG6 enhancer mutations and FRS2 duplications as angiogenesis-related drivers in bladder cancer. Nat Commun 10: $720,2019$.

53. Wang W, Kong P, Ma G, Li L, Zhu J, Xia T, Xie H, Zhou W and Wang S: Characterization of the release and biological significance of cell-free DNA from breast cancer cell lines. Oncotarget 8: 43180-43191, 2017.

54. Aucamp J, Bronkhorst AJ, Peters DL, Van Dyk HC, Van der Westhuizen FH and Pretorius PJ: Kinetic analysis, size profiling, and bioenergetic association of DNA released by selected cell lines in vitro. Cell Mol Life Sci 74: 2689-2707, 2017.

55. Bronkhorst AJ, Ungerer $\mathrm{V}$ and Holdenrieder $\mathrm{S}$ : The emerging role of cell-free DNA as a molecular marker for cancer management. Biomol Detect Quantif 17: 100087, 2019.

56. Bettegowda C, Sausen M, Leary RJ, Kinde I, Wang Y, Agrawal N, Bartlett BR, Wang H, Luber B, Alani RM, et al: Detection of circulating tumor DNA in early- and late-stage human malignancies. Sci Transl Med 6: 224ra24, 2014

57. Abbosh C, Birkbak NJ, Wilson GA, Jamal-Hanjani M, Constantin T, Salari R, Le Quesne J, Moore DA, Veeriah S, Rosenthal R, et al: Phylogenetic ctDNA analysis depicts early-stage lung cancer evolution. Nature 545: 446-451, 2017.
58. Parkinson CA, Gale D, Piskorz AM, Biggs H, Hodgkin C, Addley H, Freeman S, Moyle P, Sala E, Sayal K, et al: Exploratory analysis of TP53 mutations in circulating tumour DNA as biomarkers of treatment response for patients with relapsed high-grade serous ovarian carcinoma: A retrospective study. PLoS Med 13: e1002198, 2016.

59. Leão R, Lee D, Figueiredo A, Hermanns T, Wild P, Komosa M, Lau I, Mistry M, Nunes NM, Price AJ, et al: Combined genetic and epigenetic alterations of the TERT promoter affect clinical and biological behavior of bladder cancer. Int J Cancer 144: 1676-1684, 2019.

60. Hosen MI, Sheikh M, Zvereva M, Scelo G, Forey N, Durand G, Voegele C, Poustchi H, Khoshnia M, Roshandel G, et al: Urinary TERT promoter mutations are detectable up to 10 years prior to clinical diagnosis of bladder cancer: Evidence from the Golestan Cohort Study. EBioMedicine 53: 102643, 2020.

61. Birkenkamp-Demtröder K, Christensen E, Nordentoft I, Knudsen M, Taber A, Høyer S, Lamy P, Agerbæk M, Jensen JB and Dyrskjøt L: Monitoring treatment response and metastatic relapse in advanced bladder cancer by liquid biopsy analysis. Eur Urol 73: 535-540, 2018.

62. Vinagre J, Almeida A, Pópulo H, Batista R, Lyra J, Pinto V, Coelho R, Celestino R, Prazeres H, Lima L, et al: Frequency of TERT promoter mutations in human cancers. Nat Commun 4: 2185,2013 International (CC BY-NC-ND 4.0) License. 